\title{
Modern instruments for joint management of international projects in a pandemic
}

\author{
Elena Shatskaya ${ }^{1,}$, , Natalia Kharchenko $^{1}$, Mark Popovichenko ${ }^{1}$, and Angelina Lukyanova ${ }^{2}$ \\ ${ }^{1}$ North Caucasus Federal University, Stavropol, Russia \\ ${ }^{2}$ Kazan Federal University- Naberezhnye Chelny Institute, Russia
}

\begin{abstract}
The article provides an overview of modern instruments for business structures in a pandemic and remote work. The most popular and relevant services that allow you to organize work on a project and maintain productivity in self-isolation have been summarized. The features and advantages of software products, which may be the future of project management, have been analyzed. A review, a critical analysis of the possibilities of the digital agenda of the studied countries made it possible to determine the importance of strengthening the interaction of government authorities and business structures in the framework of the implementation of social and economic digital projects for the development of international cooperation between the Republic of Belarus and the Russian Federation. A number of prerequisites were identified as a motivational toolkit for the involvement of business entities and society in the implementation and use of digital technologies on the territory of the union states - the Russian Federation and the Republic of Belarus. A complex of restraining factors of development in the post-pandemic period for the Republic of Belarus and the Russian Federation has been identified and substantiated, which makes it possible to recognize the problems of capacity building in states and the disunity of interests of the subjects of project management.
\end{abstract}

\section{Introduction}

The Russian Federation and the Republic of Belarus are member states of the Eurasian Economic Union (EAEU). Joint international cooperation is gaining a breakthrough character due to the new opportunities of the digitalization trend. Moreover, increasing the competitiveness and economic growth of countries in modern conditions is impossible without the transition to a digital economy.

Joint cooperation of the countries through strengthening the interaction of authorities and business structures in the framework of the implementation of socio-economic digital projects, contributed to the strengthening of international cooperation between the Republic of Belarus and the Russian Federation. The successful practice of domestic business in project management emphasizes the success of developing and maintaining their own sites,

\footnotetext{
${ }^{*}$ Corresponding author: elena.sh.05@mail.ru
} 
announcing online projects, recording feedback in the post-support format. The accumulated experience is also in demand in Russian-Belarusian projects, especially in the context of a pandemic stagnation, with the use of automatic tools for setting tasks and planning and the use of CRM systems.

An analysis of Russian and foreign practice, as well as theoretical studies, made it possible to conclude that the development of a project economy in the context of digitalization declares the following challenges to public administration in Russia, specific to the Russian administrative and regulatory context: compliance with the rate of change, management flexibility, updated reporting forms, digital environment of trust, introduction of information and digital technologies into the structures of public administration $[4,5]$. To solve the identified problems, it is envisaged as follows: the creation of an information and communication technological basis for the development of the economy and social sphere and, as a result, the improvement of administrative procedures, the digitalization of public services. By 2024, as part of the implementation of the federal project "Digital Public Administration", public services that are most in demand among the population should be contactlessly available. That is, to eliminate personal visits by citizens to state (municipal) authorities, 90\% of intradepartmental and interdepartmental document flow will be transferred to digital format. The digital format of documentation and the presence of an electronic digital signature (EDS) will also affect the interaction of commercial organizations and authorities, increasing the workflow up to $70 \%$. Business and the state should have an interest in working together to support digitalization, the state of which directly affects not only the growth of economic indicators, but also the intensity of economic development.

The policy of radical economic transformations in Belarus is carried out on the basis of digital technologies, as in other EAEU member states. One of the priority directions of the strategy of the Republic of Belarus is the digitalization of the country. For the transformation of socio-economic spheres, a legislative and regulatory environment is being created, international infrastructure projects aimed at globalization are being implemented, and a crypto exchange has begun to function. As well as on the territory of the Russian Federation, the issues of development and implementation of IT-tools are being actualized in the Republic of Belarus, conditions are being created for three-way electronic interaction: citizens - business community - state (municipal) authorities. Close partnership of a number of Russian regions with Belarusian regions is based on the implementation of international cooperation agreements. Most of the Russian-Belarusian projects are being implemented under the patronage of the Chamber of Commerce and Industry, research centers, technology parks, and individual organizations. Direct investments of domestic businesses imply an injection into Belarusian transport and manufacturing industry. The Republic of Belarus actively cooperates with partners from Moscow and St. Petersburg. One of the brightest examples of international cooperation between Belarus and Russia is an investment project to create a modern agro-town in the Sakhalin Region.

However, despite the existing reserves and the readiness of the business community for further cooperation and mutually beneficial projects, the unresolved issues of a number of administrative and legislative problems may complicate the practical implementation of the integration declared in the EAEU format. The transition to effective models of interaction between business structures in the context of digital globalization of Belarus and Russia is difficult at the organizational, regulatory, methodological and economic levels without appropriate training.

The modern world is dictating its terms and challenges faced by an increasing number of organizations. The pandemic is limiting face-to-face meetings and office work, employees are moving to remote work, and this affects the productivity of companies that 
were not prepared for such conditions. In addition, time and space restrictions are erased, the capabilities of project management participants are expanded, and a new competitive environment is formed. Due to the high level of mobility of the business environment, information becomes available to a wide range of participants in international projects. It should be noted that with the growing role of information and the IT sphere, these processes contribute to the emergence of obstacles to the management of international projects and stimulate monopolization in a pandemic.

"The practice of innovative design in the field of high technologies shows that the traditional form of project management slows down the development of a project, often making it impossible to implement it due to the difficulties in obtaining information necessary for the implementation of the project, lack of experience in implementing such projects, lack of developed technologies, competitive advantages of foreign analogues" [1].

Therefore, in the sector of corporate information products, more and more services began to appear that simplify joint project work, including at the international level. Information about these services will allow the management of companies to choose the most suitable ones for themselves and, as a result, increase the efficiency of project management.

\section{Materials and methods}

The study used the methods of detailing, abstraction, comparative theoretical analysis of economic and managerial literature, a critical review and generalization of practical experience, the study of regulatory documents on the organization of strategic planning of socio-economic and scientific-technological development of the studied countries, methods of logical modeling. At the final stage, the methods of statistical data analysis were applied, their graphic and semantic interpretation was carried out.

\section{Results and discussion}

Analysis of the practice of international cooperation between the Republic of Belarus and the Russian Federation in the framework of the implementation of socio-economic digital projects made it possible to substantiate that the countries historically have a long history of integration interaction. Currently, we can talk about new opportunities for the development of interaction, especially as EAEU member countries. Among the main instruments, the following services can be distinguished, as the most popular:

- Trello;

- Notion;

- Miro;

- MindMeister;

- Slack;

- Figma;

- Zoom;

- Google online services for working with documents.

Trello is an online project management tool. "Individual resources in Trello are a highly customizable analogue of a Kanban board, consisting of columns in which you can place individual cards, which, in turn, contain additional information. Thus, a three-level hierarchy of information is realized "[2]. 
Trello gives the project manager the ability to distribute tasks, assign performers and set deadlines. This service is based on the Agile methodology (which allows you to build work on the principles of "just in time" and "the project is always ready"), namely, on the Scrum technology. "Scrum is based on empirical processes, that is, knowledge comes only with experience, and decisions can be made based on known actions. Scrum uses an iterativeincremental approach to optimize predictability and risk management "[3].

The principles of "just in time" and "project always ready" mentioned above are that the implementation of the project is carried out through the structural decomposition of work at iteration. These iterations are called the "sprint". Upon completion of the iteration, the project manager can always demonstrate the result to the customer and inform that this version is a draft and will be further refined.

Such a methodology, together with an open Trello board, allows you to build a transparent interaction with the customer, despite the fact that counterparties can be located anywhere in the world and track the process of work both from a computer and from a smartphone or tablet.

An important advantage of Trello is that this board is easily integrated into the workflow, employees quickly master the technology and complete tasks with greater motivation, since this will allow you to move the card from the "To Do" column to the "Done" column.

Notion is an advanced analogue of Trello and has more popularity in the international environment, while Trello is a domestic startup. At the same time, the expanded functionality of Notion allows you to store all incoming content in a special table "warehouse", use databases to work with information and manage tasks in different ways (task lists and calendars).

With the help of Notion, you can manage a project, maintain a content plan, share documents, take notes and attach accesses to other platforms, which makes it an absolute favorite among similar tools. However, for employees, the transition to Notion can seem difficult and time consuming. Therefore, when introducing this platform into business processes, it is important to conduct a little familiarization with the platform, which in fact is not as complex as it seems at first glance.

Another domestic collaboration product is Miro. This project resembles a blackboard that hangs in most offices and contains important notes and tasks. The advantage of this service is its flexibility, simplicity and convenience. Here you can also attach the stickers and leave notes, draw tables and columns with tasks. This tool is common among creative teams and is used for generating ideas, brainstorming and posting additional information.

MindMeister is an association mapping platform. Association or mind maps can be used in business for a variety of purposes:

- creation of a business plan;

- positioning;

- SWOT-analysis;

- branding;

- naming.

MindMeister allows you to build an easy-to-interact association map that can accommodate an unlimited number of project ideas and customize to generate new ones. This product will help you structure ideas, build a hierarchy, prioritize ideas and find new solutions to current and strategic problems in the company.

Slack is a popular corporate messenger. In it, the management can build channels of communication with employees for various purposes: personal correspondence, correspondence on the project, informal communication, discussion of ideas, interaction with the contractors. Employees can communicate with management and among 
themselves, customize the platform for themselves and receive notifications about new tasks or management ideas. In turn, management can give access to for certain chats and conversations to certain employees.

Figma is a development tool for designers, but has great value for leadership. This tool allows you to include both the management and other employees of related specialties in the development process. The platform offers a wide range of functionality for branding, website and application development. At the same time, the manager can open the project at any time and see at what stage the designer is. A programmer can get a ready-made design project and work with it most efficiently, since Figma has a separate tab for developers, where information about styles is stored in the form of ready-made code. The project manager can leave comments and make small adjustments at any time. So, using this tool, leadership of creative teams can significantly save the development time.

Zoom is an online conferencing platform. This service allows you to create and conduct online meetings, conferences, business negotiations, interviews, brainstorming sessions, etc. Meetings can be private, and unauthorized users cannot connect to them. Any conference participant can record it, if necessary. The host can appoint co-organizers to effectively manage the meetings. In addition, the participants can be divided into groups and pairs on this platform. Meeting attendees can use a virtual background that can be a corporate one. Also an important function is the ability to demonstrate your screen for project presentations in front of the customer or manager.

Google online services include a large suite of software products:

- Google Documents;

- Google Slides;

- Google Sheets;

- -Google Forms, etc.

The main advantage of these Google services is the interoperability. Management can collaborate with employees to create documents in Google Docs, design presentations in Google Slides and work in spreadsheets in Google Sheets. At the same time, these platforms can be used for different purposes:

- development of investment documents;

- creation of a business plan;

- conducting marketing research;

- creating a content plan.

In addition to these services, the Google Forms service can play an important role in project work. It can be used to conduct staff questionnaires, customer briefing and Cust Dev target groups of a startup.

In the union state of the Republic of Belarus, preference in project management is given to special services that allow you to organize a business process without leaving your home. Among the most popular solutions are Microsoft 365 cloud applications, Microsoft Teams video conferencing and teamwork service, remote workplaces and cloud storage. The centralized Microsoft Teams system is represented by several spaces.

For group work on a project, to-do lists are created. The repository of communication exchange are message boards, each of which is dedicated to a specific topic. Statistical information is professionally presented in the form of graphs that reflect the appointed dates of upcoming tasks and events in the work on the project. A separate place in the Microsoft Teams system is occupied by the cloud space that accumulates documents, files and images. Real-time mode allows you to support group chat, reflecting the responsiveness in the "ask a question - get an answer" section. Thanks to Check-in questions, questions concerning all participants are concentrated in one place and replace numerous chats and 
constant meetings. The indisputable advantage of this system is the convenience of aggregating everything you need in one place.

\section{Conclusion}

A review, a critical analysis of the possibilities of the digital agenda of the studied countries made it possible to determine the importance of strengthening the interaction of government authorities and business structures in the framework of the implementation of social and economic digital projects for the development of international cooperation between the Republic of Belarus and the Russian Federation. Analysis of the experience in the development and implementation of digital projects indicates the presence of both evolutionary and artificial components that arise with the direct participation of public authorities. A number of prerequisites were identified as a motivational toolkit for the involvement of business entities and society in the implementation and use of digital technologies in the territory of the Russian Federation and the Republic of Belarus.

1. State background. From year to year, in the countries of the Russian-Belarusian commonwealth, the amount of financial support to small and medium-sized businesses is increasing, the main goal of which is to assist small and medium-sized businesses. Today, the use of end-to-end digital technologies is one of the strategic priorities for the development of the economies of these countries. The IT sphere plays a decisive role in ensuring the technological breakthrough of countries and ensuring their competitiveness in the world market.

2. Regional background. The Russian national project "Small and Medium Enterprises and Support for Individual Entrepreneurial Initiatives" and the State Program for Supporting Small and Medium Enterprises in the Republic of Belarus provide for various support measures at all stages of the entrepreneurs' life cycle.

3. Cognitive background. In order to meet the needs for specialists in information training areas, effective interaction with universities and colleges that train specialists for the ICT sector of the economy.

The accumulation of the efforts of interaction between the authorities and business structures will make it possible to more quickly adjust the implementation of socioeconomic digital projects based on the modern requirements of regulatory legal acts and support measures at the regional level, as well as contribute to the development of international projects. Thus, the development of such interaction is impossible without the development of project management tools at the level of business structures.

In post-pandemic conditions, the information and IT-environment of Russia has acquired a different scenario of formation, namely, as part of the globalization of the information society. The spheres of industry, agriculture and transport, medicine, education are permeated with information projects. Even at the international level, there is no industry that does not have IT blocks or electronic services. Modern IT companies are forced to compete for the fact of being ahead of the creation and launch of digital services. The domestic public sector turned out to be no exception, and in order to increase the availability of social services and the provision of public services, it successfully eliminates the problems of digitalization of public administration. Of course, this provides for the full participation of the Russian Federation in the processes of information and economic integration of regions, countries and peoples, as well as the creation and development of information and knowledge as factorial project management. Thanks to the implementation of the national program "Digital Economy of the Russian Federation" dated June 4, 2019, it is planned to solve the following significant tasks: 
- development of the information society;

- raising the standard of living of the population;

- development of the socio-economic and cultural spheres of society;

- increasing the level of competitiveness of domestic goods in the field of digital technologies.

- The results of the implementation of the program by 2024 provide for:

- increase in the number of citizens using information in digital form, up to $70 \%$;

- ensuring joint activities of the state, citizens and entrepreneurs based on the use of digital technologies;

- increasing the level of labor productivity through the introduction of digital technologies;

- creating conditions for the integration of the Russian Federation into the world information society;

- carrying out legal and legally significant actions in digital form;

- increasing the level of Internet users to at least $95 \%$ of citizens.

In the period of development and digital transformation, it is impossible to overestimate the role of international projects and their management processes. The main tasks are to substantiate the advisability of choosing certain management tools and technologies to achieve the goals of the socio-economic system that make up the national economy of Russia. This is especially important for the use of advanced project management technologies and tools for digitalizing management decisions at the international level.

The process of transition to new conditions of interaction between the authorities, society and business structures in the international market has been launched, numerous social and economic digital projects are being implemented, international cooperation between the Republic of Belarus and the Russian Federation is becoming more transparent. The investigated complex of services and platforms can fully satisfy the needs of business structures in joint project management. The global crisis associated with the epidemiological situation has led to a digital breakthrough in the field of corporate information products, digital services, which have made it possible to maintain the efficiency of companies and, in some cases, save operating costs.

\section{Acknowledgements}

The study has been carried out with the financial support of the RFBR within the framework of the research project "Development of the concept of forming the effective models of interaction between the authorities and business structures at the regional level within the framework of digital integration of the Republic of Belarus and the Russian Federation", project No. 20-510-00025.

\section{References}

1. O.V. Serbskaya, Materials of Afanasiev readings, 2(15) (2016)

2. V. G. Zaitsev, A. A. Zheltova, E. V. Tibirkova, Higher education in Russia, 12 (2016)

3. Ken Schwaber, Jeff. Sutherland, The definitive Guide to Scrum: The Rules of the Game, 23 (2016)

4. National Program "Digital Economy of the Russian Federation", http://government.ru/ 
5. Official website of the Eurasian Economic Commission, http://www.eurasiancommission.org/

6. E. Yu Shatskaya, O. A. Kozlova, E. V. Sukhostav, N. A. Anashkina, O. N. Tkachenko, Perspectives on the Use of New Information and Communication Technology (ICT) in the Modern Economy, Advances in Intelligent Systems and Computing (2019)

7. V.N. Parakhina, E.G. Popkova, The Future of the Global Financial System: Downfall or Harmony, 939 (2019)

8. S. Zenchenko, Y. Radyukova, A. Zaitsev, 32nd International Business Information Management Association Conference (IBIMA): «Vision 2020: Sustainable Economic Development and Application of Innovation Management from Regional expansion to Global Growth», 3042 (2018)

9. Nadezhda V. Miroshnichenko, Svetlana V. Nedvizhay, Elena A. Ponomareva, Elizaveta V. Skiperskaya, Natalia P. Kharchenko, Perspectives on the Use of New Information and Communication Technology (ICT) in the Modern Economy, 378 (2018)

10. E.Yu. Shatskaya, N.P. Kharchenko, (2365) Economy and entrepreneurship, 8(121), 1336, 250 (2020) 